\title{
Effect of Continuous Epidural Anaesthesia in Painless Delivery
}

YUN LI*

Department of Anesthesia, Maternity and Children's Hospital of Huaibei City, Anhui 235000, P. R. China

Yun et al.: Continuous epidural anaesthesia and painless delivery

\begin{abstract}
To investigate the significance of applying continuous epidural anaesthesia in painless delivery anaesthesia, 125 cases of full-term delivery parturients who were admitted to the hospital's Obstetrics Department between November 2015 and June 2016 were selected and randomly grouped. Sixty four cases who opted for continuous epidural anaesthesia during delivery were divided into Group I, 61 cases not opted for analgesia were divided into Group II and results of delivery and the delivery course were compared between the two groups. There were 3 caesarean deliveries (4.69\%) of 64 cases in Group I, 18 (29.51\%) of 61 cases in Group II $(p<0.05)$ and the first and second stages of labor in Group I were shorter than those in Group II $(p<0.05)$. The technique of continuous epidural anaesthesia in parturient delivery is helpful to improve the quality of anaesthesia and shorten the delivery course, which shall be prioritized.
\end{abstract}

Key words: Epidural anaesthesia, painless delivery, obstetrics

The painless delivery program is one of the most critical technical methods of parturient delivery. The continuous epidural anaesthesia technique can not only improve the parturient pain index, but also shorten the stages of labor, reduce pain and consequently, its application safety can be ensured ${ }^{[1-5]}$. To investigate the practice of this anaesthetic technique in the hospital's Obstetrics Department, 125 cases of full-term delivery parturients who were admitted to the hospital's Obstetrics Department between November 2016 and June 2019 were selected for study, with the aim of improving the outcome of delivery and shortening the delivery course. This study was conducted on 125 cases of fullterm delivery parturients who were admitted to the hospital's Obstetrics Department between November 2016 and June 2019 were selected and randomly grouped. Inclusion criteria were, rimigravida women, singleton pregnancies, term pregnancy of $37-42 \mathrm{w}$, no medical diseases and, cervical dilation of 3-4 cm (beginning of the active labor phase). Women with complicated pregnancies such as preeclampsia, fetal malformation, gestational diabetes mellitus, and placenta previa, chronic illnesses such as hypertension and diabetes mellitus and multiple pregnancies were excluded from the study. Sixty four cases were included in group I, which are of 23-35 y old with mean age of $28.8 \pm 1.93 \mathrm{y}$. All were in the gestational period of $39-42$ $\mathrm{w}$ with an average of $40.6 \pm 0.21 \mathrm{w}$. Sixty one cases were included in group II of the age range 22-37 y with a mean age of $29.1 \pm 1.88$ y. These patients were in gestational week $40-42 \mathrm{w}$ with an average of $41.1 \pm 0.16$ w. There were no complications during the gestation period in these two groups and their clinical information was comparable. The technique of continuous epidural anaesthesia was applied in 64 patients in Group I during delivery, The opening degree of the uterine orifice was observed and once the opening range was between 2-3 $\mathrm{cm}$, the L3-4 gap was located to insert the needle. The puncture condition of the body was judged and the epidural catheterization device was slowly inserted to a depth of about $3 \mathrm{~cm}$ and $3.0 \mathrm{ml}$ of a mixture of fentanyl+ropivacaine was injected at a uniform rate when the body is in the intermittent stage of uterine contraction. After about half an hour, if necessary to add $6 \mathrm{ml}$ if appropriate upon evaluating the condition of the parturient and continue to administrate the medicine, at an interval of about half an hour, and each time the dosage is maintained at $6 \mathrm{ml}$ depending on the level of parturient's analgesia. If the parturient still feels the pain, the dosage shall be increased appropriately. During the second stage of delivery, it is necessary to stop the administration of anesthesia and to conduct dynamic monitoring of maternal health and neonatal status. On the other hand the 61 cases in Group II were subjected to natural delivery technique and no analgesic regimen was employed. SPSS 20.0 software 
was used to tabulate, code and analyse data. Numerical data were presented as mean $\pm \mathrm{SD}$ and categorical data were presented as number of cases. Unpaired Student t-test was used to compare the numerical difference between groups, and $\chi^{2}$-Test or Fisher's exact test was used to compare difference of categorical data between groups. The 125 parturients' delivery technique and delivery course were studied with mean $\pm \mathrm{SD}$ and $\mathrm{n} / \%$, respectively. After the data analysis, the two groups data were compared at a level of significance of $p<0.05$. There were 3 caesarean deliveries (4.69\%) of 64 cases in group I, $18(29.51 \%)$ of 61 cases in group II $(p<0.05)$ and in the meantime, the first and second stages of labor in Group I were shorter than those in Group II $(p<0.05)$, as shown in Table 1. Comparison of total delivery time, postpartum blood loss and delivery mode of parturients and neonatal asphyxia between the 2 groups showed that the total delivery time and caesarean delivery rate of the parturients in the group I were significantly lower than that in the control group, while the vaginal delivery rate was significantly higher than that in the control group and in addition, there was no significant difference in the postpartum blood loss and neonatal asphyxia, as shown in Table 2. Regarding postoperative complications, no difference in each parameter was found between the 2 groups. As shown in Table 3, there were 3 patients in group I and 2 patients in group II with nausea and vomiting who were treated with metoclopramide $10 \mathrm{mg} ; 2$ patients in group I and 1 patient in group II experienced pruritus, without the need for treatment; 2 patients in group I and 1 patient in group II developed hypotension, and were treated with $250 \mathrm{mg}$ ringer acetate and only the patient in Group II needed ephedrine sulfate $5-10 \mathrm{mg}$; 1 patient from each group developed bradycardia, who were then

TABLE 1: DELIVERY COURSE OF PARTURIENTS IN TWO GROUPS

\begin{tabular}{lcc}
\hline \multirow{2}{*}{ Group } & \multicolumn{2}{c}{ Stage of labor } \\
\cline { 2 - 3 } Group I ( $n=64$ cases) & $\begin{array}{c}\text { First stage of } \\
\text { labor }(\min )\end{array}$ & $\begin{array}{c}\text { Second stage of } \\
\text { labor }(\min )\end{array}$ \\
Group II $(n=61$ cases) & $230.16 \pm 93 \pm 70.00$ & $4 s 4.16 \pm 20.07$ \\
\hline
\end{tabular}

administered with atropine $(0.01 \mathrm{mg} / \mathrm{kg})$. All of these complications were with no significant difference (Table 3).Juan et al. reported that at the time of delivery, the uterus of a parturient would contract sharply so as to have severe pain ${ }^{[1]}$. In addition to making the body tense, a large amount of catecholamines might be released, which can inhibit adequate contraction of uterus so as to prolong the delivery course or even increase the risk of fetal distress. Therefore, attention should be paid to the optimization of delivery technique and the continuous epidural anaesthesia techniques shall be employed to ensure painless delivery. Continuous epidural anaesthesia technique emphasizes full use of epidural catheter equipment to allow anesthetics to enter the body smoothly. By blocking the pain and nervous system, the muscle group at the pelvic floor is always relaxed. In addition to accelerating the opening speed of the uterine orifice, it can also ensure the smooth reduction of fetal head and avoid the development of caesarean delivery ${ }^{[6-10]}$. In addition, through the rational application of fentanyl and ropivacaine, this anaesthesia could avoid adverse symptoms while achieving analgesic efficacy without adversely affecting the uterine contractions, so as to keep parturients in a safe awakened state during the delivery to further reduce the parturient's physical exhaustion and ensure shorter delivery course ${ }^{[11,12]}$. Of the 125 parturients included in this study, there were 3 cases $(4.69 \%)$ of caesarean delivery out of the 64 cases in group I after applying continuous epidural anaesthesia, which was significantly lower than the 18 cases $(29.51 \%)$ of caesarean delivery out of 61 cases in group II who had natural delivery technique $(p<0.05)$. In addition, the first/second stages of delivery in group I was significantly shorter than that in group II $(p<0.05)$, which indicated that the continuous epidural anaesthesia had advantages in both shortening delivery course and reducing caesarean delivery rate. To sum up, in painless delivery anaesthesia, the continuous epidural anaesthesia technique could help to shorten the first and second stages of delivery while promoting vaginal delivery and enhancing the body's analgesic quality, which shall be prioritized.Delivery is a natural process

TABLE 2: COMPARISON OF GROUPS I AND II

\begin{tabular}{lccccc}
\hline Group & $\begin{array}{c}\text { Total duration of } \\
\text { delivery }(\mathrm{h})\end{array}$ & Vaginal delivery & Caesarean delivery & $\begin{array}{c}\text { Postpartum blood } \\
\text { loss (ml) }\end{array}$ & Neonatal asphyxia \\
\hline Group I & $6.24 \pm 1.21$ & $54(90.0)$ & $6(10.0)$ & $184.65 \pm 6.43$ & $1(1.67)$ \\
Group II & $9.86 \pm 1.65$ & $42(70.0)$ & $18(30.0)$ & $182.45 \pm 5.98$ & $1(1.67)$ \\
$p$ & $<0.05$ & $<0.05$ & $<0.05$ & $>0.05$ & $>0.05$ \\
\hline
\end{tabular}

Comparison of total delivery time, postpartum blood loss and delivery mode of parturients, neonatal asphyxia between the two groups, n (\%) 
TABLE 3: COMPARISON OF POSTOPERATIVE COMPLICATION BETWEEN GROUPS I AND II

\begin{tabular}{lccc}
\hline Parameters & $\begin{array}{c}\text { Group I } \\
(\mathbf{n = 6 4 )}\end{array}$ & $\begin{array}{c}\text { Group II } \\
(\mathbf{n = 6 1 )}\end{array}$ & p-value \\
\hline Nausea and vomiting & 3 & 2 & $>0.05$ \\
Pruritus & 2 & 1 & $>0.05$ \\
Hypotension (requiring ephedrine) & 2 & 1 & $>0.05$ \\
Bradycardia (requiring atropine) & 1 & 1 & $>0.05$ \\
Respiratory depression & 0 & 0 & $>0.05$ \\
Dizziness & 0 & 0 & $>0.05$ \\
\hline
\end{tabular}

while delivery pain is usually due to the compression of the cervix in the process of uterine contractions and when uterine dilation occurs in the lower abdomen shoulder, it will also lead to pain on inner sides of two thighs and on spine, similar to most women's menstrual cramps and uterine contractions, but the pain is more intense ${ }^{[13,14]}$. The painless delivery technique has become a common way to relieve the pain of delivery in clinic. It can make the parturients finish the delivery of the foetus under the condition of complete sobriety, which effectively improves the parturients fear and lowers caesarean delivery rate. However, those who have vaginal birth contraindication and thrust anaesthesia contraindication are prohibited from employing this method ${ }^{[15-17]}$. In conclusion, the painless delivery technique can effectively reduce the pain of parturients delivery, reduce the rate of caesarean delivery, shorten the course of delivery, and ensure the safety of the mother and the infant.

\section{Conflict of interest:}

All authors report no conflicts of interest in this work.

\section{REFERENCES}

1. Ma J, Zhou J, Tian G. Effect of painless delivery with different anaesthetic methods on parturient lactation function and Apgar score of new-borns. J Hainan Med 2016;27:2546-8.

2. Li X. Study on ropivacaine combing fentanyl continuous epidural block controlled anaesthesia in painless delivery. Med Inform Dig 2016;16:43.

3. Li S. Study on Effect of different anaesthesia methods of painless delivery on parturient lactation function and Apgar score of new-born. Chin Folk Med 2016;25:67-9.

4. Ding Y, Zhang C, Zhang J, Zhang N, Li T, Fang J, et al. miR145 inhibits proliferation and migration of breast cancer cells by directly or indirectly regulating TGF- $\beta 1$ expression. Int $\mathrm{J}$ Oncol 2017;50:1701-10.

5. Ghasemi A, Fallah S, Ansari M. MiR-153 as a tumour suppressor in glioblastomamultiforme is down regulated by dna methylation. Clin Lab 2016;62:573-80.

6. Shan N, Shen L, Wang J, He D, Duan C. MiR-153 inhibits migration and invasion of human non-small-cell lung cancer by targeting ADAM19. BiochemBiophys Res Commun 2015;456:385-91.
7. Xia W, Ma X, Li X, Dong H, Yi J, Zeng W, et al. miR-153 inhibits epithelial-to-mesenchymal transition in hepatocellular carcinoma by targeting Snail. Oncol Rep 2015; 34:655-62.

8. De S, Das S, Mukherjee S, Das S, Sengupta S. Establishment of Twist-1 and TGFBR2 as direct targets of microRNA-20a in mesenchymal to epithelial transition of breast cancer cell-line MDA-MB-231. Exp Cell Res 2017;361:85-92.

9. Zhou H, Wu G, Ma X, Xiao J, Yu G, Yang C, et al. Attenuation of TGFBR2 expression and tumour progression in prostate cancer involve diverse hypoxia-regulated pathways. J ExpClin Cancer Res 2018;37:89-102.

10. Meng X, Vander Ark A, Lee P, Hostetter G, Bhowmick NA, Matrisian LM, et al. Myeloid-specific TGF- $\beta$ signalling in bone promotes basic-FGF and breast cancer bone metastasis. Oncogene 2015;35:2370-78.

11. Wei CY, Tan QX, Zhu X, Qin QH, Zhu FB, Mo QG, et al. Expression of CDKN1A/p21 and TGFBR2 in breast cancer and their prognostic significance. Int $\mathrm{J}$ ClinExpPathol 2015;48:14619-29

12. Mclaughlin SA, Staley AC, Vicini F, Thiruchelvam P, Hutchison NA, Mendez J, et al. Considerations for clinicians in the diagnosis, prevention, and treatment of breast cancer-related lymphedema: recommendations from a multidisciplinary expert asbrs panel. Ann SurgOncol 2017;24:2818-26.

13. Stubblefield MD. The underutilization of rehabilitation to treat physical impairments in breast cancer survivors. PM and R 2017;9:S317-23.

14. Rupaimoole R, Calin GA, Lopez-Berestein G, Sood AK. miRNA deregulation in cancer cells and the tumor microenvironment. Cancer Discov 2016;6:235-46.

15. Bonci D, Coppola V, Patrizii M, Addario A, Cannistraci A, Francescangeli F, et al. A microRNA code for prostate cancer metastasis. Oncogene 2016;35:1180-92.

16. Emmadi R, Canestrari E, Arbieva ZH, Mu W, Dai Y, Frasor J, et al. Correlative analysis of mirna expression and oncotypedx recurrence score in estrogen receptor positive breast carcinomas. Plos One 2015; 10:e145346.

17. Fang H, Xie J, Zhang M, Zhao Z, Wan Y, Yao Y. miRNA-21 promotes proliferation and invasion of triple-negative breast cancer cells through targeting PTEN. Am J Transl Res 2017;9:953-61.

This is an open access article distributed under the terms of the Creative Commons Attribution-NonCommercial-ShareAlike 3.0 License, which allows others to remix, tweak, and build upon the work non-commercially, as long as the author is credited and the new creations are licensed under the identical terms

This article was originally published in a special
issue, "Biomedical Research in Healthcare Setting"
Indian J Pharm Sci 2020:82(3)Spl issue5;83-85

